Milanés, I. T., \& Corcho, O. J. P. de. (2020). Psycho-pedagogical strategy to enhance intrinsic motivation towards learning

karate-do. International Journal of Life Sciences \& Earth Sciences, 3(1), 20-29. https://doi.org/10.31295/ijle.v3n1.141

\title{
Psycho-Pedagogical Strategy to Enhance Intrinsic Motivation towards Learning Karate-Do
}

\author{
Ilska Torres Milanés \\ Universidad de Oriente, Santiago de Cuba, Cuba \\ Corresponding author email: ilska.torres@inder.gob.cu \\ Osvaldo Jiménez Pérez de Corcho \\ Universidad Técnica de Manabí Portoviejo, Ecuador \\ Email: ojimenezperez9173@gmail.com
}

\begin{abstract}
The research has conducted at the EIDE, Captain Orestes Acosta of Santiago de Cuba in the sport of karate-do, to develop a psycho-pedagogical strategy to sensitize trainers, athletes, and others involved in the importance of intrinsic motivation for the teaching-learning process of the same. For the study, methods and techniques were applied such as: observation, semi-structured interviews, and surveys. The qualitative analysis of the results indicates that coaches have inadequacies in the domain of participatory methodologies and the conception and instrumentation of teaching methods, and in athletes the need to improve their teaching-learning processes predominates, wishing to develop effective strategies that favor an integral formation. The psychopedagogical strategy that is proposed has based on epistemological, theoretical, methodological, and didactic foundations that support its instrumentation and has made up of three stages with its corresponding actions. The aspects analyzed by the experts, both of the specific actions, and the strategy as a whole achieved positive assessments that validate the design for its subsequent implementation. The implementation of this psychopedagogical strategy can be a good working instrument, to optimize the type of interactions that have maintained between athletes and coaches in the said center and to promote the development of intrinsic motivation towards learning karate-do.
\end{abstract}

Keywords--- intrinsic motivation; karate-do; learning; psycho-pedagogical; strategies.

\section{Introduction}

Motivation is the key to the continuity of sports practice and the prevention of abandonment. It is essential in the enjoyment of sports activity, involuntary assistance, in achieving faster learning, among other factors that favor optimal sports performance. By analyzing the psychological components, which integrate motivation as a personality formation, a path has opened to analyze and determine the possible strategies that promote their development (Rodriguez et al., 2020). The ways to implement them will depend on multiple conditions, such as the coach's technical and psycho-pedagogical preparation, his creativity, how the teaching process is structured, the characteristics of the athletes, their interests, abilities, and individual differences, among other. Consequently, the learning of a sport must have an attractiveness that enables the self-regulation of the practitioner's behavior and must enhance significant learning that promotes the athlete's human growth.

The above, highlights why the training-learning process is vital in training, which is motivated among its links and as an important part of it. Because it is in this stage, where there are openness and availability for motivated learning based on the relationship between cognitive and affective. In the athletes there are marked differences in the level of training and previous knowledge; the social environments of origin are the very heterogeneous result of the sources of collection used; thus, these differences in patterns of behavior, motivation, and learning, pose a particular challenge to enhance high levels of motivation for the sport they practice. The training of the athlete constitutes a challenge, based on the complexity of the motivational process and the implications that such diversity involves in

ISSN 2632-9425

Submitted: March 09, 2020 / Revised: April 18, 2020 / Accepted: May 27, 2020

20 
the variety of interests, desires, needs, among others, also influenced by the characteristics of the stage of development in which they find and the socio-psychological conditions in which they operate.

Motivation can have classified as intrinsic and extrinsic; both have important implications in sports. Intrinsic motivation is one that moves individuals to perform activities because they find them pleasurable, rather than to obtain external rewards that may involve a risk to intrinsic motivation; therefore, intrinsic motivation can have used to improve the learning and performance of athletes (Deci et al., 1993; Hassandra et al., 2003). Intrinsic motivation has consequences in the perception of competencies in the learning of a sport. The competencies synthesize knowledge, skills, and values; contents that determine, the knowledge, the expertise, and the expertise of the individual, but have not reduced to these. Besides, taking into account dynamic aspects of behavior such as attitudes, motivations and other psychological factors that interact and configure it depending on the Athlete needs to respond with his performance to the demands of his sport.

The coach must be a counselor and knowledge facilitator; and in this, the development of motivation towards sport has a decisive moment. This will only be possible in the context of a didactic development and cooperative learning within the framework of social interactions. Numerous studies have been to show the role of motivation in the entire training and skills process, in a very significant way in the development of the personality of the athlete. Authors such as Rudik (1974); Csikzentmihalyi (1978); and Jones (2003), and exponents of our country such as García (2004); González (2004); Cañizares (2005), demonstrate the special value that it charges in the regulation of behavior. The training of capable, extremely motivated, and competitive athletes is one of the fundamental challenges facing sport today in Cuba. The EIDE needs to develop in its athletes both their athletic abilities and their feelings and values.

This demands the training of strong, intelligent, analytical, creative athletes, with a high technical and tactical level but at the same time developing their thinking, their emotional-motivational sphere, that what they learn acquires such a personal sense, that conditions knowledge for the next necessary learning in the development of his life. That is, during the training process the educator must ensure that the student commits himself to the task of learning. The current expectations of the contemporary sport have imposed challenges that necessarily involve scientific-methodological development, the constant search for new and better methods to face, perfect the training and preparation process of the athlete, from which Karate-Do has not been exempted, considered by many one of the 10 most practiced sports in the World. Which gives its practice, a philosophy of life and ethics that remain socially profitable today.

In recent years, it has gone through moments of significant importance, which have marked the dynamics of its. Internal development, among these, is its inclusion in the regional and continental Games of the Olympic cycle in 1993, its recognition as an Olympic sport, the statement made in 1998 by the IOC, which marked a momentous guideline for insertion in the next Summer Olympics, Tokyo 2020. As part of the Cuban sports movement, it has earned a deserved place in the system that represents the National Institute of Physical Education Sports and Recreation (INDER). Taking a massive character throughout the island for further development. Today we are working to improve, from positions of science, all the concrete processes with which Karate-Do interact in Cuba from the base link to the highest level of the high-performance pyramid, with the formation of karatekas committed to the demands of Cuban sport and the trends of the competition scenario that each one demands (Sabina et al., 2014; Rosso et al., 2012).

In the Comprehensive Program for the Preparation of the Karate-do Athlete in Cuba (2016-2010), mandatory, the pedagogical process of integral training of the same is urging to regulate the teaching and learning process in a way that allows the scope of sports mastery as a future perspective, potentiating the motivations and interests closely linked to the achievement of maximum results. Orienting the didactic process towards each of the contents of the preparation of karateka with a view to the demands of high competition, conceiving the athlete as an active participant in their learning process, and suggests a coach as a mediator and facilitator.

Despite all of the above, in the EIDE Captain Orestes Acosta in the sport of karate-do, the school category has shown a set of inadequacies shown in Figure 1. 


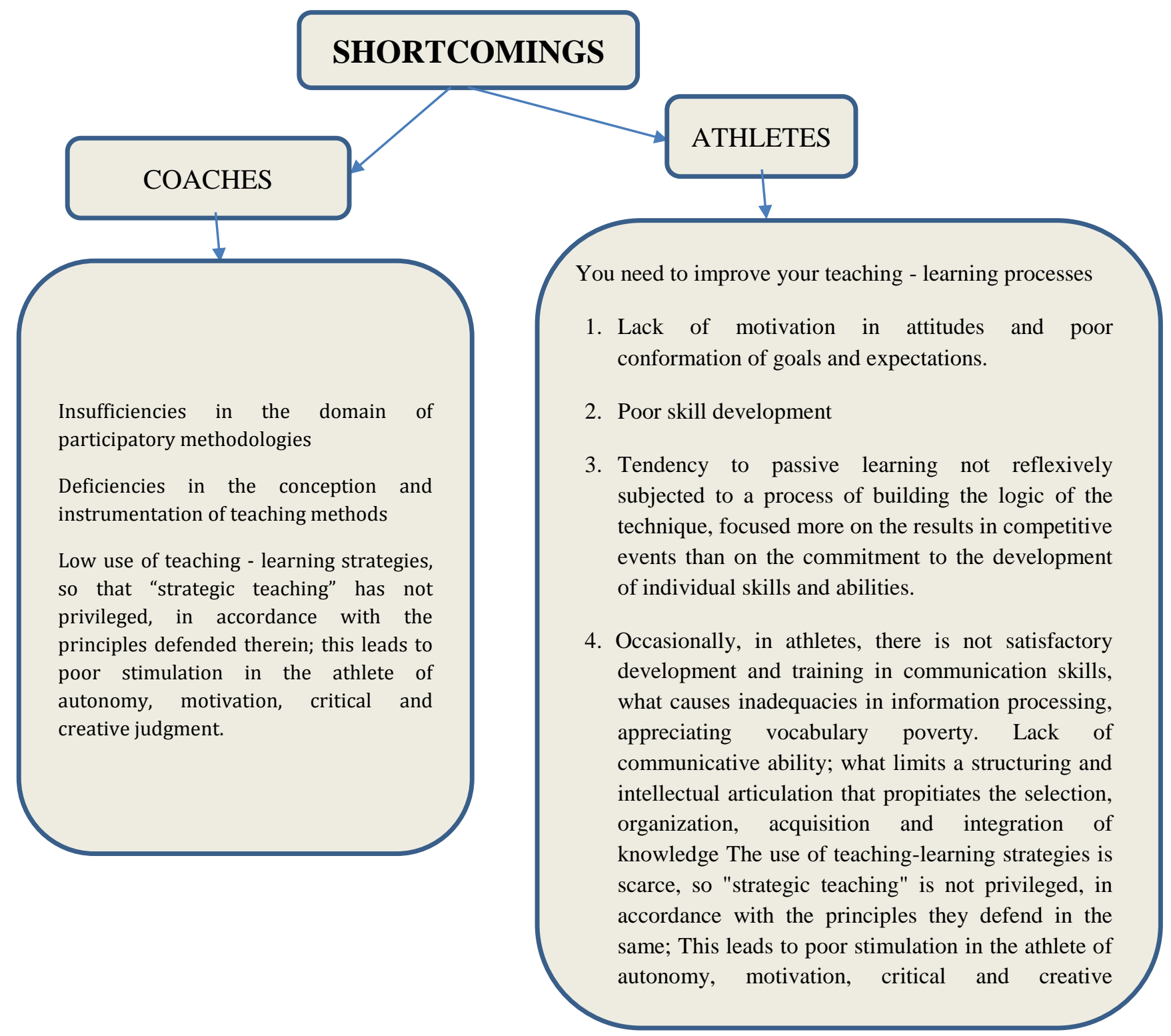

Figure 1. Insufficiency in the sport of karate-do

In correspondence with these manifestations and inadequacies that characterize the situation in problem this, this research aims to design a psycho-pedagogical strategy for coaches that enhances the intrinsic motivation towards the learning of athletes. The practical contribution of research lies in the psycho-pedagogical strategy to favor an autonomous motivational style towards learning, through the fulfillment of tasks that involve curiosity, control, fantasy, and challenge, the elevation of skill and exercise of self-determination concerning a domain orientation will promote the development of intrinsic motivation towards learning sports and mastering skills for the future (Barna \& Mircea, 2015; Tudor, 2015; Lupu, 2014). The present investigation is of great theoretical and practical importance since motivation as a psychological process compromises the dispositions, motives, needs, and interests with which the subject faces the task of learning by inducing him to act. It stimulates the will to learn to be and conditions the way of thinking of the athlete and with it his competences.

Therefore, the novelty is in the improvement of sports practice in the training process of these athletes managing to develop skills for their subsequent sports performance. From the theoretical point of view. It is possible to systematize motivation as a learning variable in the sporting context, this evident validity and actuality of the subject addressed since the lack of motivation and the poor development of skills, is a problem present in the training 
process, being able to verify in attitudes and conformation of goals and expectations that are evident throughout the process. Thus, the enhancement of intrinsic motivations towards learning the technique of a sport will facilitate the development of skills for the acquisition and awareness. This will have reversed in the formation of a more competent athlete capable of successfully facing various psychological problems from the individual or group allowing the search for effective alternatives of the solution both in training and in competition.

\section{Materials and Methods}

A mixed methodology was used to out the research; qualitative-quantitative; being a descriptive investigation of the cross-section. Which has developed with 4 coaches and 24 athletes of the school and youth categories of the karatedo of the EIDE of Santiago de Cuba. Taking into account the object of study of this research, techniques such as observations, interviews, and surveys of athletes and coaches, sports motives test, as well as the review of documents and statistical records of the coaches, have applied. Which aimed to assess the components involved in the motivation towards learning, Such as types of motivations (intrinsic and extrinsic), motivational styles, needs, expectations, goals, self-perception of skills, and cooperative learning strategies. Subsequently, a psychopedagogical strategy is developed and applied that promotes the increase of intrinsic motivation as an effective way to achieve quality technical training and a competitive athlete.

\section{Results and Discussions}

\section{Development of the psycho-pedagogical strategy}

Stage I: Diagnosis of the motivational style of athletes

Session 1: Diagnosing motivations.

Objective: Diagnosis of motivational trends in athletes.

Characterize motivational trends through:

1) Exploration of achievement and understanding needs.

2) I need to develop knowledge, skills, and competencies.

3) Exploration of the levels of regulation (reactive, adaptive, and autonomous).

4) Goal orientation (domain or execution).

4) Feeling of competition

5) Perception of control

6) Work and learning in groups and the role of socializing agents of learning.

Session 2: Identifying motivational problems and potential motivators.

Objective: To identify the potential individual and group motivators based on the motivational styles shown by the athletes.

These results will specifically guide what has related to:

1) Training management (group, individual, cooperative work; reflection on action, reflection on action, motivational reflection).

2) Task design (reproductive, productive, creative; investigators; modeled or real).

3) Administration of aids for the development of cognitive and motivational potential (direct or indirect; by the coach or by peers; individual or group; immediate or mediate; based on strategic learning that enables mastery of the logic of the skills to be developed and not the tasks themselves).

4) Learning evaluation (hetero-evaluation, coevaluation, and self-evaluation).

Stage II: Preparation of the coach in the instrumentation of didactic tasks for the development of intrinsic motivation.

Session 1: Understanding authentic tasks

Objective: To help trainers to design task systems that enhance the feeling of competition while generating behavior patterns oriented to mastery goals.

The integrative character of the other components of the process:

1) Inclusion of a cognitive demand that involves motivation (need for its realization by the practitioner) and guiding base for its execution and control 
2) the methodological organization based on motivation (need-expectations)

Didactic/pedagogical resources: Task design based on the existence of moderate discrepancies:

1) Modeling skills.

2) Illustrate the use of learning,

3) exploring the need for achievement and understanding; to evaluate current contingencies before the tasks; to identify motivating potential and stimulate patterns of behavior linked to the feeling of competence

4) Intentionally reveal the features of the context (individual or group) that define the logic of the tasks and give them relevance.

5) Provide for the step of performing tasks assisted by the coach, assisted by peers to the independent realization of them from the training space itself, taking advantage of the potential of cooperative learning.

6) Propose challenging, multidimensional tasks that require the use of thought, problem-solving, and a high degree of participation of the athlete, in interaction with others. Similarly, tasks that provide the opportunity to experience pride in the level of involvement of the athlete in its execution and resolution. These tasks require more time, greater self-regulation, athletes work on different tasks simultaneously. And that makes the progress of each athlete better controlled.

7) Properly manage external reinforcements: social reinforcement, responsibilities, privileges, public or private criticism, praise.

8) Stimulate active reflection on acting in correspondence with individual expectations and those of the coach.

Session 2: Addressing aid

Objective: Reflect on the effects of aid for intrinsic motivation.

The demands for help that athletes most frequently receive:

1) The difficulty of the task.

2) Homework orientation.

3) Homework presentation.

4) anxiety about homework

5) Attribution of achievement.

It is important to orient the reflection around the understanding of the aid as a moment of updating/enhancing skills and knowledge and not as an expression of dependence or incompetence by the athlete; in the same way, aid will be valued as an alternative to minimize anxiety about execution or expectation of failure.

Session 3: Managing motivational training

Objective: To assess the importance of the structuring and actuality of the training content as a condition for influencing the intrinsic motivation towards learning the technique.

1) The orientation of the objective towards the challenge, curiosity, control, and fantasy of the athletes before the tasks as potentializing resources of the intrinsic motivation towards the learning of the technique.

2) Inclusion of learning strategies as part of the content, in its link with teaching methods and practice using modeling and reflection.

3) Planning, regulation, and reflexive evaluation of the coach's performance: to ask questions of the type, what are the objectives that I intend to achieve? What skills are necessary to achieve learning? How to achieve the link between theory and practice? Are the procedures I am using adequate? Can I guide the construction of knowledge and cooperative learning? Have I achieved, at the end of the training, generating new expectations and learning goals in athletes? For training, what would I modify?, etc.

4) Organization of training for collaboration and cooperation among athletes: Given the social nature of learning, it is important to allow a sustained and coherent collaboration. The socialization of learning creates new opportunities for cognitive and affective activity both individually and in groups, which is related to the motivation of karateka.

5) Establishment of norms and expectations regarding respect for others in terms of their knowledge and individual differences.

6) Opportunity for choice and control of tasks: from the organization of training to allow athletes to experience the awareness of being the agents of their learning, turning them into active learners and non-passive. 
7) Contextualization of the learning of the technique linked to the basic skills associated with the possibility of capturing and understanding the relationships that determine the facts that are an expression of the development of sports competitions.

8) Use of authentic tasks, problems, and evaluations based on the knowledge and logic of their discipline; develop them in a way that generates expectations for learning.

9) Offer opportunities for practice and inquiry to favor the interest of value, as well as self-efficacy towards knowledge and skills.

10) Creation and use of diverse media and resources as a challenging aspect of the task that helps them put a concrete form to some of their models.

11) Provision of models or different representations, thinking aloud, giving directions, providing useful feedback, guiding athletes through the first part of the task, etc.

12) To achieve an adequate interaction of the coach with the athlete: that the relations occur in a framework of acceptance, mutual trust, and respect; that a climate of affectionate relationships that contributes to safety and to form a positive and realistic self-image in athletes is favored; that the coach takes into account the athlete's abilities to move them forward.

The session ends with the assessment of the feasibility of implementing changes concerning those aspects pointed out by themselves as hindering or ignored to motivate.

Session 4: Working on the Motivating Potential (emerging motivation) and goals

Objective: To reflect on the need to conduct learning as an intrinsically motivated activity that allows strengthening the orientation towards mastery goals.

Begin the session by asking:

How to generate projects and expectations in athletes that favor learning and mastery of content? How to enhance the need for skill development? What strategies to use?

Based on the debate that has generated, the following didactic guidelines have offered:

1) Knowing or diagnosing needs and expectations based on diversity: It is an important element since knowledge of the needs and expectations of athletes will allow a better choice of means, methods, and strategies that are effective and attractive.

2) To guide the learning through strategies promoting curiosity, challenge, and search of the skill (see annex) To

3) Promote the significant learning in the athletes starting from favoring the understanding and the oral expression, critical thinking, practical bonding, etc.

4) Promote personal work adapted to the different possibilities of the group. Offer a process that provokes active and searching work, challenge, curiosity, control, and fantasy of the athletes having as support guidelines for the activity, as well as the use of various materials to support learning or through learning. Simulation or modeling that puts them in situations that are not present.

5) Guide the entire team to analyze their learning and skills and know-how to ask for help. Offer clues to avoid repeated failures. Promote self-assessment, inform the athlete of their process, and boost self-esteem. Athletes who believe they are competent to enjoy their tasks more and show greater intrinsic motivation than those who consider their competition low.

6) Pose the applicability of learning to other content areas, to experiences in skills and values of your life, with questions posed by the coach, or that the athlete himself can ask if he is motivated to do so.

7) Create a new system of needs that transcends the current ones, stimulating the interest of the athletes, in learning and trying to make the learning go beyond the immediate and the instrumental, project the learnings to new present or future situations, cause the athlete to relate What you already know with what you learn, teach to apply knowledge to topics of interest to the athlete.

8) Promote the personal involvement of the enjoyment of learning in the face of the challenges of the individual's task and skills in the development of their skills through positive reinforcement.

The trainers will have instructed in the knowledge of some favorable keys for the development of intrinsic motivations in athletes towards learning such as Prize

9) Management when preferences have shown for tasks that involve a challenge, rather than for easy jobs.

10) Allow performing tasks to satisfy curiosity and personal interest rather than to get approval in the framework of the tasks oriented by the coach himself.

11) Reward and reinforce attempts to achieve goals for yourself and not depending on the coach or other colleague.

12) Encourage the use of self-assessments. 
13) Direct the assessment of successes and failures to internal criteria, rather than based on external criteria.

14) Generate the need for competition, the need for autonomy, and that of feeling in the relationship.

15) Awareness of interests and learning purposes.

16) Give more value to the fact of learning than to succeed or fail.

17) That they consider intelligence and skills as something modifiable.

18) That they focus more attention on the experience of learning than on external rewards.

19) Facilitate their autonomy and control by showing the relevance and significance of the tasks using as resources the curiosity, the challenge, and the search for the skill.

The session ends with the realization of a brainstorm about potential motivators that have identified in their athletes.

Session 5: Closing

Objective: Demonstration by the trainers of the use of the didactic guidelines as concrete didactic actions for the management of motivational training

The session begins taking up the didactic guidelines worked in the previous sessions in such a way that it serves as a basis and condition for the modeling of its implementation in a training (orientation, exercise, or generalization). The development of this modeling will be developed in small groups, each group will choose a set of guidelines that favor the autonomous motivational style; it will be presented to the group which will be making indications and suggestions about the proposal. Aspects of importance should have specified, such as:

The role of the coach in the field of motivation will focus on inducing motives in their athletes in regards to their learning and behaviors to apply them voluntarily to training, giving meaning to modeling tasks and providing them with a specific purpose, so that athletes develop a real taste for training and understand its usefulness. Among the main reasons that encourage athletes is to learn, achieve success, avoid failure, be valued, and get rewards.

The motivation towards cognitive-affective factor learning, either explicitly or implicitly, present in every learning activity, in any pedagogical procedure, and not as a technique or method of teaching.

The management of motivation related to the following factors:

a) Characteristics and demands of the activity

b) Goals or purposes established for such activity,

c) The purpose that has sought with the completion of the task.

Therefore, it can have said that the purposes pursued through the management of motivation towards learning the technique should include:

1) Arousing interest in the athlete and directing their attention towards new goals

2) Stimulating the desire to learn leads to an effort for the development of his skills.

3) Direct interests and efforts towards the achievement of appropriate purposes and the realization of defined purposes.

4) The real possibility that the athlete has to achieve the goals proposed and the perspective assumed when training.

5) Let the athlete know how to act, what learning process to follow (how to think) to successfully face the tasks and problems that arise.

In the end, the group will have asked for personal criteria and experiences acquired during the time of program development using the PNI as a tool (positive, negative, and interesting aspects). This tool will allow evaluating the development and improvement of the program in later implementations. As a closing element, coaches will have provided bibliographic information that allows the consolidation of all aspects addressed in the psycho-pedagogical strategy.

Stage III Analysis of the partial results obtained during the implementation of the first stage of the psychopedagogical strategy

During the implementation of the first session, we start by explaining to the coaches the general objective of the strategy to raise awareness and involve them, as well as develop expectations regarding the implementation process. Then some terms and concepts necessary for the trainers have specified during the process of application and evaluation of the diagnostic tools that will have presented. Some of these concepts have the emerging motivation, mastery goals, types of feedback, motivational styles, TEC. 
The coaches referred to the need to generate these spaces for exchange and reflection on the dynamics of the learning process, specifically, how to enhance the intrinsic motivation towards learning the technique, as an effective way of developing a more competitive athlete.

Everyone's involvement was achieved during the development of the first, stage of the psycho-pedagogical strategy, recognized the insufficient preparation in the subject particularly in the vision of the didactic resources that can be available to generate motivational training and how to engage the athlete with the development of their training; the trainers. we're contributing ideas for the evaluation and analysis of the motivational tendencies in the athletes, which generated interest for the challenge they would face, evaluating as part of their methodological improvement to contribute to raising the quality of the work they undertake; as a resource to influence the dynamics of training and increase the effectiveness of learning. There was evidence of involvement in the task and willingness to implement the strategy as an expression of the coaches' commitment to this work. The development of the first session has intended to provide trainers with diagnostic tools that allow the evaluation of the motivational tendencies of their athletes. To complete the same, the four coaches involved have chosen. As a fundamental tool, he has guided to conduct a group interview, at the first meeting, to obtain information from athletes regarding motivational tendencies. The following indicators have proposed to have fundamentally taken into account:

1) Exploration of achievement and understanding needs.

2) I need to develop knowledge, skills, and competencies.

3) Self-concept.

4) Feeling of competition

5) Work and learning in groups and the role of socializing agents of learning.

6) Expectations they have (this indicator can be developed in groups or individually).

Another technique to use is the instrumentation of an exercise that must have developed by the coach, related to the existence of a series of previous knowledge, which will allow evaluating the systematization of learning and skills, in addition to allowing the evaluation of the sources of intrinsic motivation. As a challenge and control. Starting from the orientation of the task, the group's beliefs are investigated in the accomplishment of the task (in terms of success or failure), obtaining information regarding the perception of control, the orientation of goals, and exploration of the levels of regulation. The level of understanding of both the tasks and the guidance given to the coaches was adequate considering that they are non-psychologist coaches, but they have a wide reference on motivation. However, it was necessary to provide more information regarding the strategies as they are more familiar with the more concrete vision of the skills.

There was consensus in recognizing how these diagnostic instruments could be applied as a way to complement the initial knowledge that they always try to have about athletes - although empirically and referring to their abilities - not so, to motivational aspects while relative belief predominates at low levels of motivation. The topics have also worked on to form the group interview and by consensus, it was determined that it would explore the following issues: achievement needs; self-concept, perception of skills, goal orientation, and feedback made by coaches, and effectiveness of teamwork. During the development of the second session, of the diagnostic evaluation of the motivational tendencies of the athletes, the trainers from the group interview used could verify that the development of the intrinsic motivation has favored by the prevalence of tasks that require levels of motivational regulation in real scenarios, influencing this in the determination of goals. There is a low level of perception of competence, which has manifested by the lack of security in the domain of knowledge and skills.

The needs for achievement, competence, and autonomy towards the task have more focused on the social relations system, that is, on the interest of the group to overcome the task with good results, associated with the nature of the execution goals that are present since Success has defined by the results in the competition rather than the best execution. Most athletes agree that they rarely feel competent to face any problem, indicating deficiencies in the development of learning towards the skills necessary for a successful future performance, influencing their selfperception of achievement, valuing the learning goal as difficult and with few Probability of success, which affects both the motivation towards learning, and low perception of competence. Aspects these linked significantly to the motivation of achievement. Another aspect considered by coaches has related to the conception in the practice of proper management of training and interactions with athletes. An important aspect of the planning by the training coach, the optimal use of the types of grouping structures, the optimal use of coach-athlete feedback, as well as the administration of aids and being aware of how they favor motivation. Of the athlete, mainly using keys provided by the coaches who inform the athletes about their abilities and acquisition of skills.

On the other hand, the value that for them has to avoid failure can have inferred. The effort before the tasks has sufficiently directed towards the demonstration of personal worth. The athlete has evaluated from the norms and social comparison. Errors or failures are valued as a lack of ability or worth demonstrating the vulnerability of their 
self-esteem. The preference for external reinforcing agents as evaluation, the approval of the group, and the coach; are aspects that connote their motivational tendencies.

\section{Conclusion}

1) The problems encountered in training can have overcome with the implementation of a psycho-pedagogical strategy.

2) The coach as a facilitator of learning under the constructivist principles in training dynamics allows the design of intrinsically motivating tasks.

3) The development of an autonomous motivational style, the orientation towards mastery goals, the development of intrinsic motivations, the self-regulation of the technique learning, as a whole allows valuable results and the achievement of quality in the learning of sports skills and abilities.

Based on the results obtained, the coaches who participated in the implementation of the psycho-pedagogical strategy raised awareness of the need to change the dynamics of training in how to face motivational aspects; highlighting the need to look for alternatives that promote the increase of intrinsic motivation as an effective way to achieve training.

\section{References}

Alfonso, E., \& Bárcena, D. (2019). Retos y desafíos para el deporte cubano en 2019. Publicado en Cuba en el Deporte, La Habana, Cuba.

Barna, I., \& Mircea, D. (2015). Psycho-pedagogical Counselling. An important stage in students' teaching career orientation. Procedia-Social and Behavioral 1044-1049. https://doi.org/10.1016/j.sbspro.2015.02.201

Cañizares, M. (2005). Psicología y equipo deportivo. Editorial INDER, La Habana.

Castellanos, B., Livina U., \& Fernández, A.M. (2003). La gestión de la actividad de Ciencia e innovación tecnológica y la competencia investigativa del profesional de la Educación en Pedagogía 2003. Curso 18.

Castelló, A. (1995). Modelos de inteligencia y modelos de instrucción: relaciones teóricas y funcionales. Psicologías teóricas y funcionales. Psicología de la Instrucción III. Madrid: Nuevas perspectivas.

Csikszentmihalyi, M. (1978). Intrinsic rewards and emergent motivation. The hidden costs of reward: New perspectives on the psychology of human motivation, 24(3), 205-216.

Deci, E. L., Driver, R. E., Hotchkiss, L., Robbins, R. J., \& Wilson, I. M. (1993). The relation of mothers' controlling vocalizations to children' s intrinsic motivation. Journal of experimental child psychology, 55(2), 151-162. https://doi.org/10.1006/jecp.1993.1008

Díaz Barriga, F. \& Hernández, E. (2000). Estrategias docentes para un aprendizaje significativo. Colombia: Colección Docente del Siglo XXI. McGraw-Hill. Interamericana SA

Dósil, J. (2004). Psicología de la Actividad Física y el Deporte. Edición McGraw-Hill Interamericana de España, ISBN: 84-481-4067-2

Estrategia Integrada del Deporte Cubano (2017). Instituto Nacional de Deportes, Educación Física y Recreación de Cuba.

Fariñas, L. G. (2005). Psicología, Educación y Sociedad. Un estudio sobre el desarrollo humano. La Habana: Editorial Félix Varela.

Fuentes, H. \& Cruz, S. (2001). La conducción del Proceso de Enseñanza Aprendizaje en la Educación Superior. Monografía. CeeS. "Manuel F. Gran", Universidad de Oriente.

González, D.J. (2008). Psicología de la motivación. La Habana: Edit. Ciencias Médicas.

González, F.A. (2001). Autorregulación del aprendizaje, una tarea difícil. Revista electrónica Iber- Psicología. Vol. 6 $N^{o} 1$

González, R. L. (2004). Psicología en el campo de la salud y la enfermedad. La Habana: Editorial Científico Técnico.

Gutiérrez, M.O. (2005). Educación y entrenamiento basados en el concepto de competencias Implicaciones para la Acreditación de los Programas de Psicología. Revista Mexicana de Psicología. (22),12-18 
Hassandra, M., Goudas, M., \& Chroni, S. (2003). Examining factors associated with intrinsic motivation in physical education: a qualitative approach. Psychology of sport and exercise, 4(3), 211-223. https://doi.org/10.1016/S1469-0292(02)00006-7

Hernández, A. (2003). Psicología del Deporte. Volumen III. Aplicaciones 1. Editor Tulio Gutterman, Buenos Aires, Argentina.

Jones, J. M. (2003). TRIOS: A psychological theory of the African legacy in American culture. Journal of Social Issues, 59(1), 217-242. https://doi.org/10.1111/1540-4560.t01-1-00014

Louis, C. (2016). Programa Integral de Preparación del Deportista: Universidad de las Ciencias de la Cultura Física y el Deporte.

Lupu, C. (2014). The Analytical-Synthetic Presentation of the Psycho-Pedagogical Paradigm of Discipline Didactics. Procedia-Social and Behavioral Sciences, 149, 508-512. https://doi.org/10.1016/j.sbspro.2014.08.299

Menéndez, F. y Estua, J. (2013). Entrenamiento psicológico para contribuir al desarrollo de la preparación psicológica. EFDeportes, Revista Digital, Año 18, Núm.184

Monereo, C. (1999). Enseñar y aprender estrategias. Barcelona: Praxis.

Mora, J., García, J., Toro, S. \& Zarco, J. (2000). Cuestionario de Estrategias Cognitivas en Deportistas. Madrid, TEA Ediciones.

Nisbet, J., \& Shucksmith, J. (1987). Estrategias de aprendizaje. Madrid: Grupo Santillana de Ediciones.

Pozo, J.I. (2003). Adquisición de Conocimiento. Madrid: Ediciones Morata.

Rodriguez, J. A. P., Perez, H. M. D., \& Sabates, H. R. R. (2020). Psychological actions to increase tolerance to frustration in pitchers: category 15-16 years. International journal of health sciences, 4(1), 1-7. https://doi.org/10.29332/ijhs.v4n1.377

Rosso, C., Zenhäusern, R., Müller, A. M., \& Valderrabano, V. (2012). Karate-do-the path of the empty hand. SportOrthopädie-Sport-Traumatologie-Sports Orthopaedics and Traumatology, 28(1), 12-16. https://doi.org/10.1016/j.orthtr.2012.02.013

Rudik, PA (1974). Psikhologiya: uchebnik dlya institutov fizicheskoy kul'tury [Psychology: textbook for institutes of physical culture]. Moscow, FIS .

Sabina, M., Ioana-Sorina, L., Elena-Andreea, L., \& Radu, P. (2014). Manifestations of some personality traits in karate do. Procedia-Social and Behavioral Sciences, 117, 269-274. https://doi.org/10.1016/j.sbspro.2014.02.212

Tudor, L. S. (2015). The specific of using educational strategies in teaching and learning psycho-pedagogical disciplines from preschool and primary pedagogy specialization. Procedia-Social and Behavioral Sciences, 180, 709-714. https://doi.org/10.1016/j.sbspro.2015.02.182 